\title{
Platelet-type Arachidonate 12-Lipoxygenase in Mouse Gastrointestinal Tract
}

\author{
Michihiro Nakamura, Shozo Yamamoto and Kazunori Ishimura* \\ Department of Biochemistry, Tokushima University, School of Medicine, Kuramoto-cho, Tokushima 770 and \\ *Department of Anatomy, Tokushima University, School of Medicine, Kuramoto-cho, Tokushima 770
}

Received for publication October 1, 1997

\begin{abstract}
12-Lipoxygenase enzyme oxygenates the position 12 of arachidonic acid, and produces 12S-hydroperoxy-arachidonic acid. When mouse gastrointestinal tract was immunostained with an antiserum against human platelet 12-lipoxygenase and examined by light microscopy, positively-stained cells were found in the epithelium of stomach and small and large intestines. Electron microscopic immunohistochemistry revealed that the positively-stained cells were open-type enteroendocrine cells. The endocrine cells had many granules of
\end{abstract}

heterogeneous sizes, forms and internal structures, and most of the granules had electron lucent area. 12-Lipoxygenase was localized in the cytoplasm, but not in the nucleus, plasma membranes and other subcellular organelles. Double immunostaining revealed that all 12-lipoxygenasepositive cells contained serotonin. With an antiserum against 12-lipoxygenase isozyme of porcine leukocytes, no positively-stained cells were observed in gastrointestinal epithelium.

Key words: 12-Lipoxygenase, Arachidonic acid, Serotonin, Mouse intestine, Immunohistochemistry

\section{Introduction}

Arachidonate 12-lipoxygenase is an enzyme which oxygenates the position 12 of arachidonic acid. The product is $12 S$-hydroperoxy-arachidonic acid. Enzymological, immunological and molecular biological studies have demonstrated the occurrence of two distinct isoforms (platelet-type and leukocyte-type) of the enzyme [20]. The leukocyte-type 12-lipoxygenase has been detected not only in leukocytes but also in several nonhematopoietic tissues, including bovine trachea [6], porcine anterior pituitary gland [19], canine brain [14], rat pancreatic islets [17], human adrenal cortex [4] and rat pineal gland [5]. However, the tissue distribution of the platelet-type enzyme has not yet been investigated in detail. In addition to platelets of various animal species, the enzyme has so far been found only in human and mouse keratinocytes [1, $2,7,9,13,18]$. Recently we prepared an antiserum against recombinant 12-lipoxygenase of human platelet, and immunostained immature and mature murine megakaryocytes [12] and keratinocytes [13]. By the use of this antiserum, our further studies on other tissues

Correspondence to: Shozo Yamamoto M.D., Ph.D., Department of Biochemistry, Tokushima University School of Medicine, Kuramotocho, Tokushima 770, Japan. demonstrated the occurrence of this enzyme in mouse gastrointestinal tract as will be reported in this paper.

\section{Materials and Methods}

Materials

OCT compound was purchased from Miles Laboratories (Naperville, IL), osmium tetroxide and paraformaldehyde from Merck (Darmstadt, Germany), Vectastain ABC kit, biotinylated goat anti-rabbit IgG antibody and fluorescent isothiocyanate (FITC)-conjugated antimouse IgG from Vector Laboratories (Burlingame, CA), 3, 3'-diaminobenzidine (DAB) from Dojin (Kumamoto, Japan), Epon-812, DDSA, MNA and DMP-30 from TAAB (Reading, UK). A rabbit antiserum against porcine leukocyte 12-lipoxygenase [10] and a rabbit antiserum against recombinant 12-lipoxygenase of human platelet [12] were prepared and characterized as described previously. Rabbit antisera against serotonin (Immuno Nuclear Corp., Stillwater, MN), vasoactive intestinal polypeptide (Immuno Biological Labs., Tokyo, Japan), human pancreatic polypeptide (Miles Labs., Elkhart, IN) and somatostatin (Dakopatts, Santa Barbara, CA), were kindly provided by Drs. Kunio Ii and Toshiaki Sano of Pathology Department of our school. Mouse monoclonal antibody against serotonin was purchased from Biogenesis 


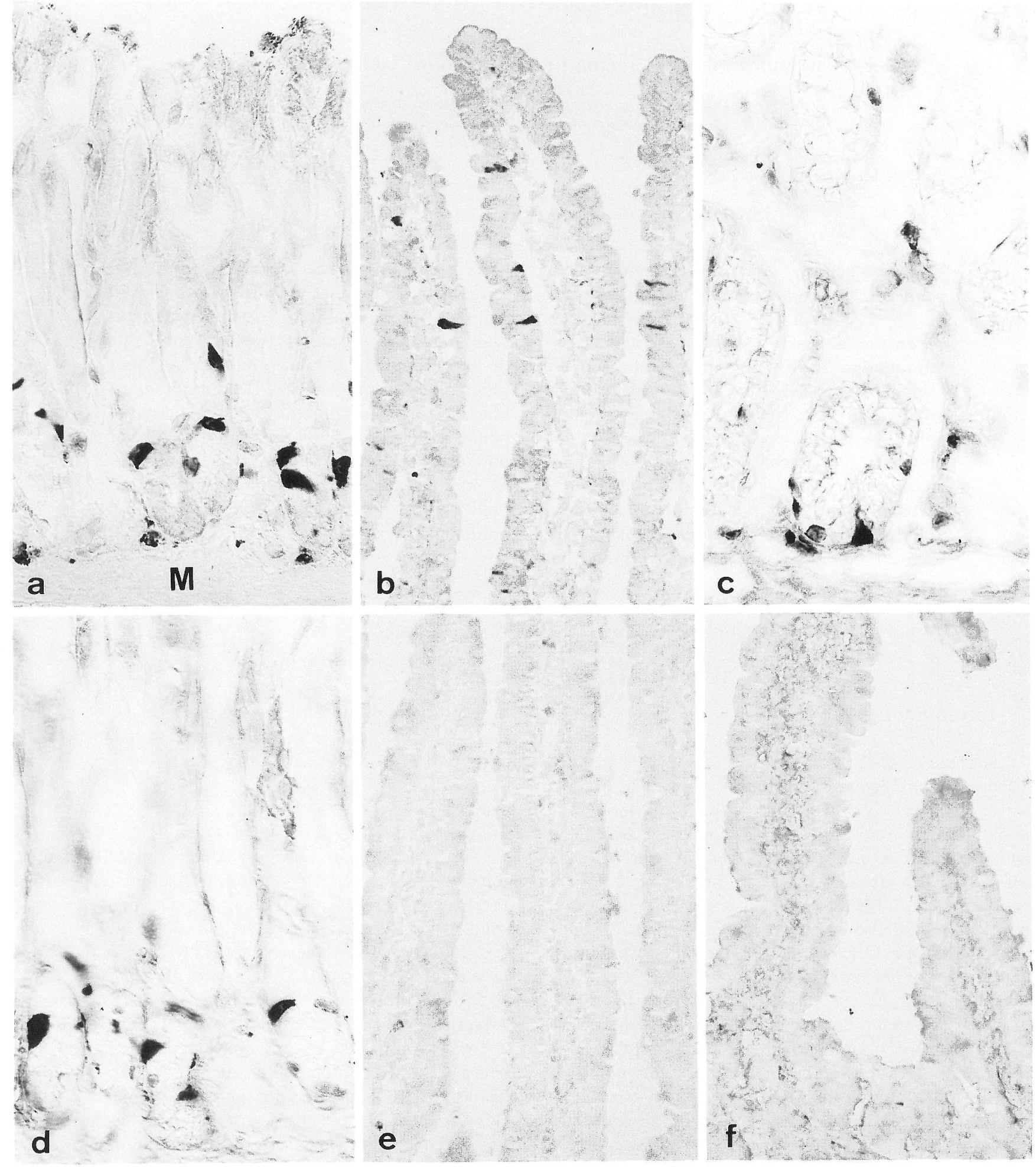

Fig. 1. Light microscopic immunohistochemistry of 12-lipoxygenase in mouse gastrointestinal tract. Positively-stained cells are scattered in the epithelium of the stomach (a) and small (b) and large (c) intestines with anti-platelet 12-lipoxygenase antiserum. With the aid of antiserotonin antiserum numerous positively-stained cells are found in the epithelium of the stomach (d). No immunopositive cells are present in control section of small intestine treated with preimmune rabbit serum (e) and antiserum against porcine leukocyte 12-lipoxygenase (f), respectively. M, muscularis mucosae. a, $\mathbf{d} \times 340 ; \mathbf{b}, \mathbf{e}, \mathbf{f} \times 160 ; \mathbf{c} \times 310$. 
(Poole, UK), and rhodamine-conjugated goat anti-rabbit IgG from Cappel (Durham, NC).

\section{Immunostaining for light and electron microscopy}

Anesthetized C57BL/6 mice were perfused transcardially with $4 \%$ paraformaldehyde in $0.1 \mathrm{M}$ phosphate buffer ( $\mathrm{pH}$ 7.4). Stomach and small and large intestines were removed, cut into small blocks, submerged in fixative for $12 \mathrm{hr}$ at $4^{\circ} \mathrm{C}$, and then rinsed sequentially with $20 \mathrm{mM}$ potassium phosphate buffer at $\mathrm{pH} 7.4$ containing 10, 15 and 20\% sucrose for $4 \mathrm{hr}$. The tissues were placed in OCT compound and frozen at $-20^{\circ} \mathrm{C}$. Frozen sections $(6-\mu \mathrm{m}$ thickness) were cut in a cryostat, and mounted on polyL-lysine-coated glass slides. For immunostaining with antiserum against human platelet 12-lipoxygenase, the avidin-biotin-peroxidase complex method was performed as described previously [12]. As control experiments the sections were treated with preimmune rabbit serum (1:2,000 dilution) or an antiserum against porcine leukocyte 12-lipoxygenase $(1: 1,000)$. For identification of 12-lipoxygenase immunoreactive cells, some of the sections were treated with each of the following antisera: antiserotonin $(1: 5,000)$, anti-vasoactive intestinal polypeptide $(1: 1,600)$, anti-human pancreatic polypeptide $(1: 800)$ and anti-somatostatin $(1: 1)$. For double immunostain- ing, some sections were incubated with anti-serotonin monoclonal antibody $(1: 100)$ at $4^{\circ} \mathrm{C}$ overnight. After rinsing with phosphate-buffered saline, the sections were incubated with a FITC-conjugated goat anti-mouse IgG (1:100) for $1 \mathrm{hr}$ at $32^{\circ} \mathrm{C}$, rinsed with phosphate-buffered saline, and then incubated with anti-12-lipoxygenase antiserum at $4^{\circ} \mathrm{C}$ overnight. After washing with phosphatebuffered saline, rhodamine-conjugated anti-rabbit IgG (1: 200) was applied for $1 \mathrm{hr}$. Following several rinses the stained sections were coverslipped with $80 \%$ glycerol in phosphate-buffered saline. Immunofluorescent labeling for serotonin (FITC) and 12-lipoxygenase (rhodamine) in the same area were photographed in turn by changing filters.

\section{Results}

\section{Light microscopic immunohistochemistry of 12-lipoxy-} genase in mouse gastrointestinal tract

By the use of an antiserum against platelet-type 12lipoxygenase, positively-stained cells were scattered in the epithelium of mouse gastrointestinal tract. The shape of the positive cell was pyramidal in the stomach and large intestine (Fig. 1a, c), and columnar in the small intestine (Fig. 1b). In addition to the epithelial cells, positively-

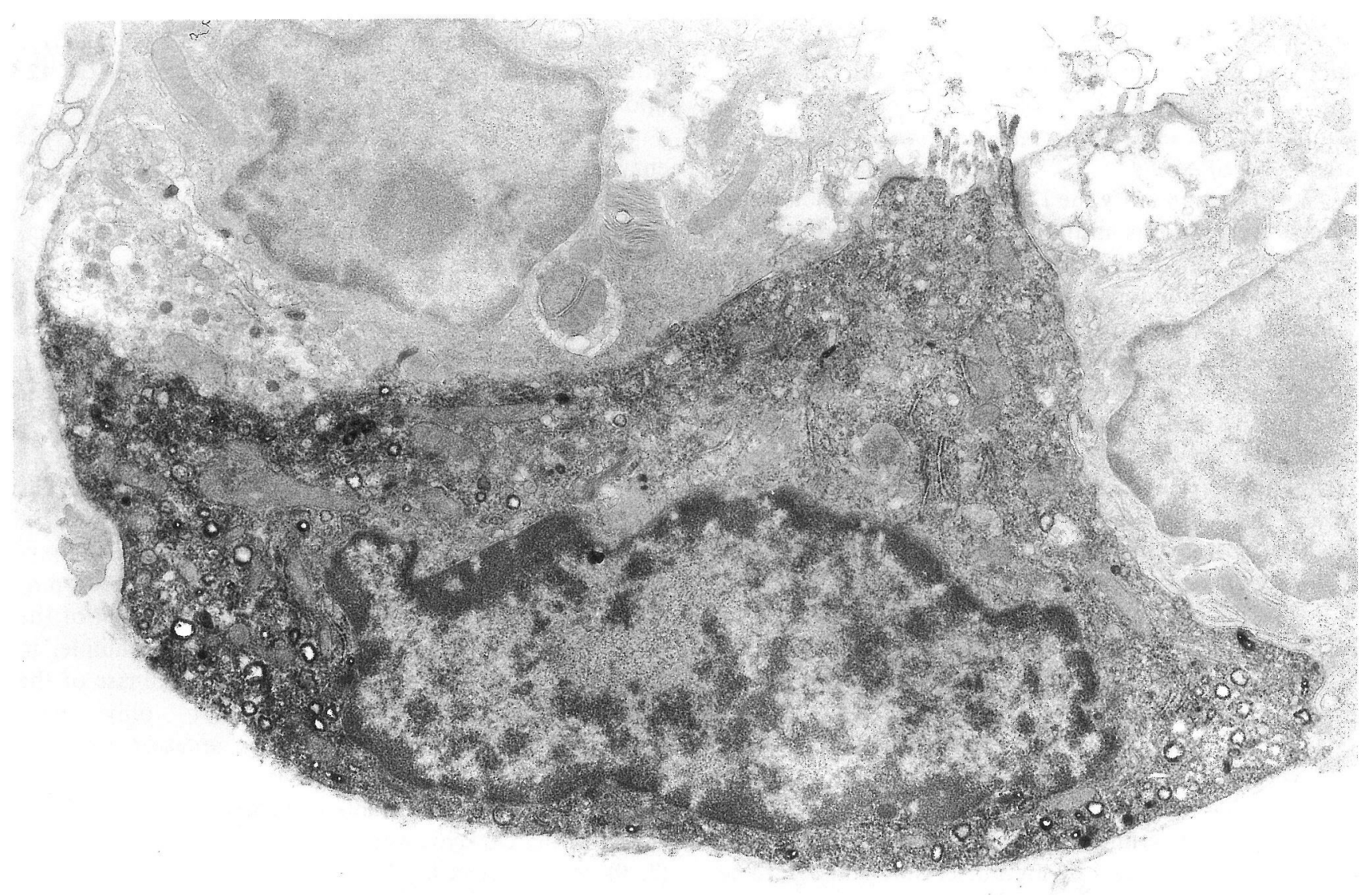

Fig. 2. Electron microscopic immunohistochemistry of 12-lipoxygenase in mouse stomach. By the use of antiserum against human platelet 12lipoxygenase, immunoreaction products are found in the cytoplasm of the enteroendocrine cell. $\mathrm{N}$, nuclei. $\times 12,000$. 
stained round cells were observed in the lamina propria (Fig. 1a), but these cells were also stained by preimmune rabbit serum. Thus, only the epithelial cells were immunostained specifically with anti-12-lipoxygenase antiserum. For immunoabsorbance test, the anti-12-lipoxygenase antiserum was incubated with the purified recombinant 12-lipoxygenase of human platelet at $4^{\circ} \mathrm{C}$ overnight. The antiserum thus treated failed to stain any cell in the epithelium of mouse gastrointestinal tract. The use of a preimmune rabbit serum and an antiserum against 12lipoxygenase isozyme of porcine leukocytes failed to stain the gastrointestinal epithelial cells (Fig. 1e, f). These results indicated the presence of the platelet-type 12-lipoxygenase rather than the leukocyte-type enzyme in mouse gastrointestinal tract.

\section{Electron microscopic immunohistochemistry of 12-lipoxy- genase}

The positively-stained cells with anti-12-lipoxygenase antiserum were further examined by electron microscopy. As shown in Fig. 2, the positive cell had microvilli at the apex and many granules in the cytoplasm. The granules were of heterogeneous sizes, forms and internal structures, and most of them had an electron lucent area. These findings suggest that the positively-stained cells were opentype enteroendocrine cells. Immunoreaction products were found in the cytoplasm, but not in the nucleus, mitochondria, secretory granules, Golgi apparatus, rough endoplasmic reticulum and plasma membranes.

\section{Identification of the 12-lipoxygenase-immunoreactive enteroendocrine cells}

We tried to identify the 12-lipoxygenase-immunoreactive cell using various antibodies against the hormones of enteroendocrine cells. The distribution pattern of the $12-$ lipoxygenase-immunoreactive cells was very similar to that of serotonin-immunoreactive cells (Fig. 1d), but different from those of vasoactive intestinal polypeptide, pancreatic polypeptide and somatostatin. Namely, serotonin-immunoreactive cells were detected in the epithelium of stomach and small and large intestines. Therefore, double immunofluorescence labeling was carried out using antisera for 12-lipoxygenase and serotonin. As shown in Fig. 3, all 12-lipoxygenase-positive cells (Fig. 3a) were also stained by an antibody for serotonin (Fig. 3b).

\section{Discussion}

By an immunohistochemical study using anti-12lipoxygenase antibodies we could demonstrate the presence of 12-lipoxygenase of the platelet-type in mouse gastrointestinal tract. The cells, which were positively stained by an antiserum against human platelet 12-lipoxygenase, were not stained by an antiserum against porcine leukocyte 12-lipoxygenase. We tried to detect the enzyme activity with arachidonic and linoleic acids as substrates to catalytically distinguish the two isozymes of 12-lipoxy-
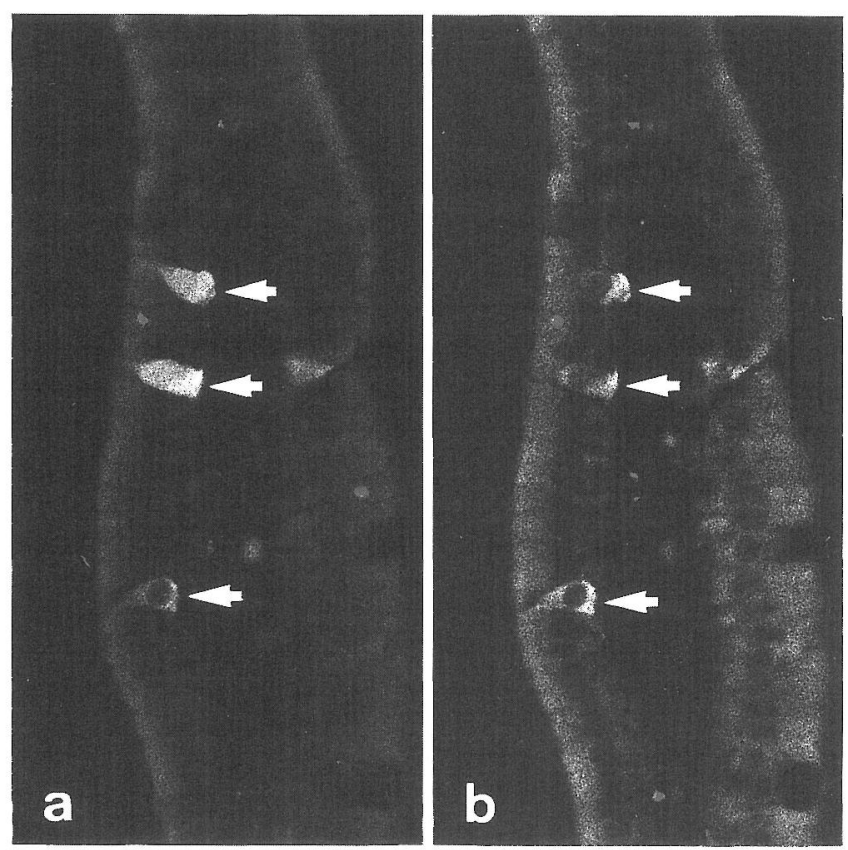

Fig. 3. Double immunostaining of 12-lipoxygenase (a) and serotonin (b) in small intestine. 12-Lipoxygenase-positive cells are also stained by an antibody for serotonin (arrows). a, $\mathbf{b} \times 300$.

genase [20]. However, there were only a small number of the immunostained cells, and it was difficult to collect a sufficient amount of the enteroendocrine cells for the 12lipoxygenase assay.

Electron microscopic observation revealed that the enzyme was localized in the cytoplasm of enteroendocrine cells, but not in the nucleus, plasma membranes or subcellular organelles. In accordance with this finding, we previously immunostained mouse bone marrow cells with the anti-platelet 12-lipoxygenase antiserum. The positively-stained cells were platelets, megakaryocytes and eosinophils, and the 12-lipoxygenase was detected in the cytoplasm of these cells, but was hardly detectable in the plasma membranes and intracellular organelles [13].

In view of the distribution pattern and ultrastructural characteristics, the 12-lipoxygenase-immunoreactive cells were associated with serotonin-containing cells. Indeed, double immunostaining clearly showed that the 12-lipoxygenase-immunoreactive cells contained serotonin. However, we could not rule out the colocalization of the 12-lipoxygenase with other hormones. For example, in porcine anterior pituitary cells the 12-lipoxygenase of the leukocyte-type was colocalized not only with gonadotrophin but also with other anterior pituitary hormones [8].

In addition to mouse enteroendocrine cells, 12-lipoxygenase of platelet-type was found in mouse epidermal cells $[2,9]$ and platelets [2, 12]. These three cell types have membrane-bounded granules. Namely, the cells of granular layer of epidermis have lamellar granules, and platelets have dense bodies and $\alpha$ and $\lambda$ granules. It is well 
known that the platelet dense bodies take up and store serotonin from the plasma.

The biological significance of 12-lipoxygenase has not been fully understood [20]. Stimulatory effects of 12lipoxygenase metabolites of arachidonic acid have been reported for various endocrine systems; LH-RH [3], melatonin [16], insulin [15], gonadotrophin [8] and aldosterone [11]. In addition, the presence of leukocytetype 12-lipoxygenase was demonstrated in various endocrine cells on biochemical, molecular biological and immunohistochemical bases: porcine anterior pituitary cells [19], rat pancreatic islet $\beta$-cells [17], human adrenal glomerulosa cells [4] and rat pineal cells [5]. Our present work is the first immunohistochemical demonstration of a platelet-type 12-lipoxygenase present in endocrine cells. It is possible that the platelet-type enzyme is also involved in the hormone release by enteroendocrine cells.

\section{Acknowledgments}

We thank Dr. Kunio Ii of Pathology Department of our school for expert advice in the immunostaining of serotonin. This work was supported by grants-in-aid for scientific research from the Ministry of Education, Science, Sports and Culture of Japan, the Japanese Foundation of Metabolism and Disease, the Japan Foundation for Applied Enzymology, Ono Pharmaceutical Company, Kissei Pharmaceutical Company, Sankyo Company, Japan Tobacco Incorporation and Takeda Pharmaceutical Industry.

\section{References}

1. Chang, W. -C., Ning, C. -C., Lin, M. T. and Huang, J. -D.: Epidermal growth factor enhances a microsomal 12-lipoxygenase activity in A431 cells. J. Biol. Chem. 267; 3657-3666, 1992.

2. Chen, X. -S., Kurre, U., Jenkins, N. A., Copeland, N. G. and Funk, C. D.: cDNA cloning, expression, mutagenesis of Cterminal isoleucine, genomic structure, and chromosomal localizations of murine 12-lipoxygenases. J. Biol. Chem. 269; 13979-13987, 1994.

3. Gerozissis, K., Vulliez, B., Saavedra, J. M., Murphy, R. C. and Dray, F.: Lipoxygenase products of arachidonic acid stimulate LHRH release from rat median eminence. Neuroendocrinology 40; 272-276, 1985.

4. Gu, J. -L., Natarajan, R., Ben-Ezra, J., Valente, G., Scott, S., Yoshimoto, T., Yamamoto, S., Rossi, J. J. and Nadler, J. L.: Evidence that a leukocyte type of 12-lipoxygenase is expressed and regulated by angiotensin II in human adrenal glomerulosa cells. Endocrinology 134; 70-77, 1994.

5. Hada, T., Hagiya, H., Suzuki, H., Arakawa, T., Nakamura, M., Matsuda, S., Yoshimoto, T., Yamamoto, S., Azekawa, T., Morita, Y., Ishimura, K. and Kim, H. -Y.: Arachidonate 12lipoxygenase of rat pineal glands: catalytic properties and primary structure deduced from its cDNA. Biochim. Biophys. Acta 1211; 221-228, 1994.
6. Hansbrough, J. R., Takahashi, Y., Ueda, N., Yamamoto, S. and Holtzman, M. J.: Identification of a novel arachidonate 12-lipoxygenase in bovine tracheal epithelial cells distinct from leukocyte and platelet forms of the enzyme. J. Biol. Chem. 265; 1771-1776, 1990.

7. Hussain, H., Shornick, L. P., Shannon, V. R., Wilson, J. D., Funk, C. D., Pentland, A. P. and Holtzman, M. J.: Epidermis contains platelet-type 12-lipoxygenase that is overexpressed in germinal layer keratinocytes in psoriasis. Am. J. Physiol. 266; C243-C253, 1994.

8. Ikawa, H., Yamamoto, K., Takahashi, Y., Ueda, N., Hayashi, Y., Yamamoto, S., Ishimura, K., Irahara, M. and Aono, T.: Arachidonate 12-lipoxygenase in porcine anterior pituitary cells: its localization and possible function in ganadotrophs. $J$. Endocrinol. 148; 33-41, 1996.

9. Krieg, P., Kinzig, A., Ress-Löschke, M., Vogel, S., Vanlandingham, B., Stephan, M., Lehmann, W. D., Marks, F. and Fürstenberger, G.: 12-Lipoxygenase isoenzymes in mouse skin tumor development. Mol. Carcinog. 14; 118-129, 1995.

10. Maruyama, T., Ueda, N., Yoshimoto, T., Yamamoto, S., Komatsu, N. and Watanabe, K.: Immunohistochemical study of arachidonate 12-lipoxygenase in porcine tissues. $J$. Histochem. Cytochem. 37; 1125-1131, 1989.

11. Nadler, J. L., Natarajan, R. and Stern, N.: Specific action of the lipoxygenase pathway in mediating angiotensin II-induced aldosterone synthesis in isolated adrenal glomerulosa cells. $J$. Clin. Invest. 80; 1763-1769, 1987.

12. Nakamura, M., Ueda, N., Kishimoto, K., Yoshimoto, T., Yamamoto, S. and Ishimura, K.: Immunocytochemical localization of platelet-type arachidonate 12-lipoxygenase in mouse blood cells. J. Histochem. Cytochem. 43; 237-244, 1995.

13. Nakamura, M., Yamamoto, S. and Ishimura, K.: Subcellular localization of arachidonate 12-lipoxygenase and morphological effect of its overexpression on murine keratinocytes. Cell Tissue Res. 288; 327-334, 1997.

14. Nishiyama, M., Okamoto, H., Watanabe, T., Hori, T., Hada, T., Ueda, N., Yamamoto, S., Tsukamoto, H., Watanabe, K. and Kirino, T.: Localization of arachidonate 12-lipoxygenase in canine brain tissues. J. Neurochem. 58; 1395-1400, 1992.

15. Pace-Asciak, C. R. and Martin, J. M.: Hepoxilin, a new family of insulin secretagogues formed by intact rat pancreatic islets. Prost. Leukot. Med. 16; 173-180, 1984.

16. Sakai, K., Fafeur, V., Normand, BV -L. and Dray, F.: 12Hydroperoxyeicosatetraenoic acid (12-HPETE) and 15-HPETE stimulate melatonin synthesis in rat pineals. Prostaglandins 35; 969-976, 1988.

17. Shannon, V. R., Ramanadham, S., Turk, J. and Holtzman, M. J.: Selective expression of an arachidonate 12-lipoxygenase by pancreatic islet $\beta$-cells. Am. J. Physiol. 263; E828-E836, 1992.

18. Takahashi, Y., Reddy, G. R., Ueda, N., Yamamoto, S. and Arase, S.: Arachidonate 12-lipoxygenase of platelet-type in human epidermal cells. J. Biol. Chem. 268; 16443-16448, 1993.

19. Ueda, N., Hiroshima, A., Natsui, K., Shinjo, F., Yoshimoto, T., Yamamoto, S., Ii, K., Gerozissis, K. and Dray, F.: Localization of arachidonate 12-lipoxygenase in parenchymal cells of porcine anterior pituitary. J. Biol. Chem. 265; 23112316, 1990.

20. Yamamoto, S.: Mammalian lipoxygenases: molecular structures and functions. Biochim. Biophys. Acta 1128; 117-131, 1992. 